\title{
The Role of Nurses Providing Information to Parents about the Prevention of Overweight and Obesity in Children
}

\section{E. Zacharova (Eva Zacharova)}

St. Elizabeth University of Health and Social Work, Bratislava, SK

\section{Original Article}

\section{E-mail address:}

eva.zacharova@seznam.cz

\section{Reprint address:}

Eva Zacharova

St. Elisabeth University of Health and Social Sciences

Nam. 1. Maja 1

81000 Bratislava

SK

Source: Clinical Social Work and Health Intervention Pages: $106-113$
Volume: 9

Issue: 2

Cited references: 24

\section{Reviewers:}

Vlastimil Kozon

Vienna General Hospital - Medical University Campus, AT

Ivan Bartosovic

St. Elisabeth University of Health and Social Work, Bratislava, SK

\section{Key words:}

Obesity. Overweight. Prevention. General Nurse. Education.

\section{Publisher:}

International Society of Applied Preventive Medicine i-gap

CSWHI 2018; 9(2): 106 - 113; DOI 10.22359/cswhi_9_2_16 @ 2018 Clinical Social Work and Health Intervention

\section{Abstract:}

This article focuses on parents' awareness about the prevention of overweight and obesity in children and its' use in the everyday life of respondents. Here an important role is played by a General Practitioner for Children and Adolescents, where the General Practitioner and his Nurse help to educate parents about the issues, risks and prevention of overweight and obesity. By identifying problematic areas in the prevention of overweight and obesity in children, the negative 
consequences of the family's lifestyle and thus the lifestyle of the child can be minimized in the future.

\section{Introduction}

Problems of overweight and obesity in children are covered by various Institutions in the Slovak Republic. Despite the efforts of the National Obesity Prevention Program and its strategies to address overweight and obesity issues, with the aim of reducing the number of obese persons by 2025 , the number of obese patients continues to increase (22). "Despite the fact that childhood obesity is receiving much attention from doctors, parents and the media, none of the measures so far have a long-term effect" (18). General Practitioners for Children and Adolescents are increasingly confronted with children who are considerably overweight. In the preventive examinations of children, especially between the ages of 10 and 15, we recorded higher body weight, higher BMI; abnormal levels of lipids in the blood, hyperglycemia; dyslipidemia; high cholesterol and triacylglycerols; increased blood pressure. Preventive examinations should include counseling in which Nurses and Physicians can positively influence and educate parents in a timely manner about proper child nutrition, suitable exercise and prevention. This should also include informing parents about the consequences of overweight and obesity in children as well as solutions to the problem.

Obesity is referred to as the third most common chronic disease of civilization and an epidemic of the new millennium.

"The mechanism of the development of obesity is not yet fully elucidated but many factors play a role. Genetic factors and environmental influences are involved in the development of obesity.“(3).

Kozuchova and Baskova are convinced that improper nutrition as well as an excessive consumption of a diet that does not match the age of the child leads to a disruption of his or her health and a deterioration of their overall nutritional status.

"The WHO reported in 2015 that 2.3 billion people were overweight and over 700 million people were obese. The WHO estimates that in 2020, two-thirds of all diseases in the world will be connected to our dietary habits"(21).

According to Parizkova, Lisa et al., the incidence of childhood obesity in European countries is not the same (16). It is mostly accepted in countries with higher economic levels.

"Many factors are involved in the onset and duration of obesity such as biological, psychological and social factors" (10).

- Biological factors include the long-term disparity between the intake and expenditure of energy that occurs through overeating or reduced physical activity.

- Psychological factors contribute not only to the emergence but also mainly to the duration of obesity. It is related to eating habits and emotions.

- Social factors are associated with education, social status, employment, financial income, gender, nationality and race. The risk factors of obesity mentioned by Covisa (2) coincide with Malkova, I., Malkova, H. (10).

- Importance is also attributed to cultural and economic factors.

"Factors that affect individuals and cause obesity are numerous and involve not only the biological aspects but also the psychological and social spheres of the individual"'(2). 
- The occurrence of obesity is also linked to education. Obesity is more common in families where the parents have a lower level of education. Covisa assumes that a woman's education affects obesity in children more than a man's education.

- Environmental factors as the cause of overweight and obesity are described by Hainerova (5), Marinov et al. (12). The authors consistently point out that a human is naturally different in her/his ability to actively change the environment in which she or he lives.

- Hainerova (5), Ondriova et al. (14) add that prenatal factors also contribute to the development of obesity.

- Vitek (21) divided the risk factors of obesity into uninfluenced reasons (age, gender, genes, factors such as gut flora, virus infections, brain activity, overweight of parents, height, birth weight, breastfeeding, household income, education) and influenced reasons (nutrition, movement, lack of sleep, stress, leisure time). According to Vitek, it is proved that obesity in children is more common if one or both parents are over-weight (21).

- The lifestyle of the family as a risk factor in childhood obesity is often written and discussed. Marinov et al. (12), Ondriova and Sinaiova (15) report that the main source of childhood obesity is the family lifestyle.

"All the paths to study the causes of childhood obesity leads to the family" (4).

Obesity as a disease occurs where there are inappropriate lifestyles, bad habits and poor behavior (7).

Lately, Pediatrics have been intensely interested in how to halt the rising trend of overweight and obesity in children. They claim that the actual prevention of common obesity is the most effective treatment for obesity (11).

\section{Practical part:}

\section{Objective of the Survey}

To find out about the parents' awareness of issues, risks, overweight and obesity prevention in children and their use in the everyday life of the respondents.

\section{Sub-objectives}

- To find about parental awareness of overweight and obesity prevention in children.

- To investigate the influence of genetic predisposition on the development of overweight and obesity in children.

- To find if breastfeeding has an effect on the development and development of overweight and obesity in children.

- To find the effect of parents' physical activity towards overweight and obesity in children.

- To determine the extent to which parents' lifestyle influences the risk of overweight in children.

\section{Patients and Survey Methods}

The group of respondents consisted of parents of those children registered in the General Practitioner's Office of the selected Medical Facility who met the criteria needed for this research. This group was represented by a total number of 150 citizens from the Slovak Republic: 134 women $(89.33 \%)$ and 16 men (10.67\%) who had children aged 10 to 15 years. The research was carried out after the written consent of the children's parents was provided and this research was performed during the period lasting from October 2017 to January 2018. A quantitative scientific method was chosen for this purpose. The questionnaire research technique was used to collect the necessary information and this data was then converted into a statistical file in Excel. The questionnaires for the group of respondents were 
prepared and available in both printed format and electronic format and contained 25 questions.

\section{Discussion}

Hypothesis 1 has confirmed that parents with a higher education are better informed about child obesity than parents with a lower education. Obesity as a chronic disease was identified by $52.29 \%$ of respondents with higher education, with more women responding to this than men. Covisa (2) assumes that a woman's education has a greater impact on childhood obesity than that of men. Parizkova, Lisa et al. (16) agree with Covisa that parental education influences the composition of the diet, as well as the selection of foods and the subsequent preparation of food. From the surveyed questionnaire survey data, it was confirmed that women are more interested in the health of the child, thus agreeing with Vitka's statement (21) that there is a relationship between education and a healthy lifestyle upbringing. The presumption by Frankova, Parizkova, Malichova et al. (4) that parents with a higher education are better able to select the acquired knowledge for the health of the child, was confirmed in the results of this research. Hainerova (5), who shares with Svacina, Bretsnajdrova (19), said that the most common complications of childhood obesity are metabolic and cardiovascular problems. Evaluated data from this research was consistent with this that of the authors whereby respondents identified cardiovascular and metabolic problems as being the most common. Respondents with a higher education attach greater importance to the overall unhealthy diet $(69.69 \%)$ as a cause of obesity in children. And according to Marinov, Barcakova, Nesrtova, Pastucha et al. (12) this includes not only overeating but also unhealthy and inappropriate food.
Hypothesis 2 confirmed that a child who has at least one parent who suffers from obesity has a tendency to also be overweight and obese more often than a child of slim parents. In respondents' family, overweight or obesity occurs in $63.34 \% ; 28$ (18.68\%) of the respondents admitted that their children are currently overweight or obese. The percentage of parents and children with overweight or obesity differs by only $2.67 \%$ which suggests that overweight respondents have overweight children. This confirms the theory of Svacina, Bretsnajdrova (19), who are convinced that genetics is a factor that affects the occurrence of obesity in the family. In 2011, Pavelekova, Peterkova (17) devoted research to the study of the presence of obesity in parents and their children. They assumed that parents with higher BMI values would have children with higher BMI values. The authors found that the incidence of obesity in men $(9.27 \%)$ was higher than in females $(3.97 \%)$. The results of this research and with their research are the same. Overweight or obesity was reported by more men $(37.50 \%)$ than women $(29.85 \%)$. In National Anthropological Research in the Slovak Republic (6), which took place in 2011 (ÚVZ Slovak Republic, Institute of Hygiene, LFUK) found that the weight of children from 2001 to 2011 increased in boys from 1.6 to $5 \mathrm{~kg}$ on average; in girls from 0.6 to $3.4 \mathrm{~kg}$. The results of the research further indicate that in all age groups from 7 to 18 years there was a significant increase in BMI, in boys by 0.8 to $1.5 \mathrm{~kg} . \mathrm{m}^{-}$ 2; in girls ranging from 0.4 to $1.3 \mathrm{~kg} . \mathrm{m}^{-2}$.

Hypothesis 3 confirmed that non-breastfed children are overweight more often than breastfed children (a child that was fully breastfed for at least 6 months). Several authors agree on the validity of the claim about the protective effect of breastfeeding. Hainerova (5), Marinov, Pastucha et al. (11), Nevoral et al. (13) where breastfeeding has 
the ability to prevent overweight and obesity in children at a later age and is supplemented by an indication of how long it is necessary to breastfeed in order for breastfeeding to be effective. It was therefore determined in this research whether respondents were breastfed and how long they had breastfed their own children. From the evaluated data, it was discovered that the majority of the respondents, $110(73.34 \%)$ were breastfed in childhood. And 100 (66.67\%) of the respondent's children were breastfed. The opinions of the 97 of the respondents $(64.67 \%)$ on the protective effect of breastfeeding is the same as the opinions of the authors. The survey of maternal attitudes towards breastfeeding by Ondriova, Fertaĺova, and Hadasova (14) in 2015 shows that mothers consider breastfeeding to be the healthiest and most natural diet for a child towards improving their health. Based on the survey data obtained in this research, we can identify with the conclusion of the survey by the authors. The data obtained from this research and the claims of Parizkova, Lisa et al. (16) are the same whereby one of the factors influencing the length of breastfeeding coincides with the level of education (of the respondents).

Hypothesis 4 has confirmed that the children whose parents participate in regular exercise activities have more physical activity themselves than children whose parents do not do so. According to Marinov, Barcakova, Nesrtova, Pastucha (12), it is proved that if the parents do participate in regular sporting activities, then neither do their children. Although regular sports activity has been shown to have a low number of respondents in their research, their children regularly exercise 2 to 3 times a week. This means that even if the parents only participate in sport activities on an occasional basis then this can be a model for their children to follow. This is confirmed by the statement by Kovacs, Babinska (8) that children have a natural relationship to exercise.

A group of authors (20) was devoted to investigating the physical activity and leisure time of the population of children in the Slovak Republic. A survey on the physical activity of children was carried out by RUVZ Komarno, 2nd Pediatric Clinic LF UK, DFNsP Bratislava, Institute of Physiology LF UK Bratislava in 2007. The results of the work present by a group of authors showed that school children spend their leisure time with no exercise and only mostly passive activities. The research results in this work differ slightly compared to that of the authors. Passive activity was identified by $30.77 \%$ of the respondents whereas $51.90 \%$ of the respondents were identified towards having active activities. Surprisingly, however, is that this research showed that $17.33 \%$ of respondents do not have time for their children. So, the question arises whether these children spend their leisure time without passive parenting or with active activities.

Hypothesis 5 confirmed that children of parents who have an unhealthy diet are more prone to overweight and obesity than children of parents who have a healthy diet. Marinov, Pastucha et al. (11) state that a prerequisite of a healthy lifestyle of the parents is a healthy diet and exercise regimen. Parizkova, Lisa et al. (16) place great importance on the lifestyle of the family. However, the evaluated data from this research indicates that most respondents are aware of the impact of their lifestyle on their children but nonetheless up to $107(71.39 \%)$ of the total number are either eating healthily occasionally or not at all. The results of this research coincide with the statement by Prochotska, Kovacs (18), who report that the absence of eating breakfast has an effect on overweight and obesity in children. Based on the results of this research, it has been confirmed that 
up to 31 children currently suffer from being overweight which basically corresponds to the number of children (i.e. 32 children) who are aged between 10 and 15 years of age who do not eat breakfast at all. A group of authors (1) conducted a study focusing on the nutrition and diet of children in relation to the risk of obesity. The greatest attention was paid to breakfast. The results show that $61.7 \%$ of children regularly eat breakfast and $17.2 \%$ of children do not eat breakfast at all. By comparing their results with the results of this research we can conclude that since 2007 the parents' awareness of breakfast and its' importance in the healthy life of their children has increased.

\section{Improvement recommendations}

\section{Recommendations for management:}

- Provide continuous education for pediatric Nurses in the field of nutrition and physical activity of children aged from 0 to 19 years of age (courses, training, further education).

\section{Recommendations for Nurses of chil-} dren and adolescents:

- Nurses involved in the primary prevention stage will provide advice regarding breastfeeding.

- Nurses will be interested in the healthy diet of the child and family.

- Nurses will be interested in the child's exercise regime.

\section{Recommendations for Nurses in chil- dren's wards:}

- Nurses in secondary prevention roles will motivate a child to reduce weight.

- Nurses will be interested in the family's lifestyle.

\section{Conclusion}

Overweight and obesity is affecting ever younger children. Prevention is more effective than follow-up treatment. Based on the results obtained, it is clear that more attention should be paid by Nurses towards parents who have a lower education. It is necessary to deepen the education and upbringing regarding their health so that they can learn and use this new knowledge in practical ways. Prevention of child overweight and obesity is in the interest of the whole society and strengthening the role of Nurses as educator in primary and secondary care could be of importance.

\section{References}

1. BABINSKA K, VITARIUSOVA E, ROSINSKY J et al. (2007) Boarding School Schedule in Slovakia. Pediatrics for practice. [online]. Solen. 8th year, No 4/2007. pp. 217-220. [Quoted 2007]. ISNN 13394231. Available on the Internet: http://pediatriapreprax.sk/index.php?page $=$ pdfview \&pdf_id=2608\&magazine_id=4.

2. COVISA J (2004) Practical Health. 1. Publisher. Bratislava: Young Years, 2004. 687 pp. ISBN 80-10-00390-5.

3. FABRYOVA L (2016) Obesity v Numbers. In: Bedeker Health. Bratislava: RE-PUBLIC, 2016, no. 03, grade. XII, pp. 8 - 9. ISNN 1337-2734.

4. FRANKOVA S, PARIZKOVA J, MALICHOVA E et al. (2015) Overweight Child and Their Problems. Praha: Portal, 2015. 256 pp. ISBN 978-80-262-0797-9.

5. HAINEROVA I (2009) Children's obesity. Praha: MAXDORF Jessenius (2009) 114 pp. ISBN 978-80-7345-196-7.

6. HAMADE J, jana.hamade@uvzsr.sk, (2017) Tab_Grafy-CAV_SR_2011_01. [e-mail]. Message for M. Baumgartner (martina. baumgartnerova@gmail.com). Posted 3. November 2011, 12:27 am. [Quoted 201804-04]. Available on the internet: https:// 
mail.google.com/mail/u/0/\#search/jana.hamade\%40uvzsr.sk/15f819d76854baee.

7. HANZLIKOVA A et al. (2004) 2. . Community Nursing. Publisher. Martin: Enlightenment, 2006. 280 pp. ISBN 80-8063-213-8.

8. KOVACS L, BABINSKA K et al. (2008) Obesity, Nutrition and Physical Activity in Children. Bratislava: Comenius University, Faculty of Medicine, Bratislava, 2008. 44 s. ISBN 978-80-223-2552-3.

9. KOZUCHOVA M, BASKOVA M (2013) Occurrence of Overweight and Obesity in Children in School Age and Adolescence in Central Slovakia. [online]. Bratislava: Hygiene. II. year. No 12/2005. pp. 501-505. [cited 2005]. ISSN 1339-424X. Available on the Internet: http:/www.solen.sk/pdf/ Majercak.pdf.

10. MALKOVA I, MALKOVA H (2014) Obesity with small steps to a big change. Praha: Forsapi, 2014. 191 pp. ISBN 978-80-87250-24-2.

11. MARINOV Z, PASTUCHA D et al. (2012) Practical Child Obesitology. Praha: Grada Publishing, 2012. 224 pp. ISBN 978-80247-4210-6.

12. MARINOV Z, BARCAKOVA U, NESRTOVA M, PASTUCHA D (2011) With Children Against Obesity. Prague: IFP Publishing \& Engineering, 99 pp. ISBN 978-8087383-07-0.

13. MECIAKOVA M, FOLTIN V, KRCMERY V, OLAH M, RIDOSKO J, GAZIKOVA E, CAUDA R (2017) Health emergencies during flights (Case reports and Mini-review). In: Clinical social work and health intervention. / Peter G. Fedor-Freybergh, Michal Olah. - Austria: I-GAP, Vienna, 2017. - ISSN 2076-9741/Online, ISSN 2222-386X. - Roč. 8, č. 3 (2017) s. 54-57.

14. NEVORAL J et al. (2003) Nutrition in childhood. 1. Publisher. Jihlava: Publisher H \& H, 2003. 434 pp. ISBN 80-86-022-93-5.

15. OLAH, M (2016) Alternative child custody "Cochem's model" 1. Ed. - Nadlac: Editura Ivan Krasko, 2016. - 221 - ISBN 9789731077060.
16. OLAH, M, IGLIAROVA B (2016) Social services in legislation and practice. 1. ed. - Bratislava: IRIS s.r.o., 2016. - 398 - ISBN 978-80-89726-58-5.

17. ONDRIOVA I, FERTALOVA T, HADASOVA L (2017) A Survey of Attitudes of Mothers for Breastfeeding. [online]. Solen. 18th year No 02/2017. pp. 139-142. [cited 201702-15]. ISSN 1803-5264. Available on Internet: http://www.pediatriepropraxi.cz/pdfs /ped/2017/02/15.pdf.

18. ONDRIOVA I, SINAIOVA A (2016) Obesity in Children and Possibilities of its Early Prevention. Slovak Physician. Grade. 7-8, pp. 76-81.

19. PARIZKOVA J, LISA L (2007) Obesity in Childhood and Adolescence - Therapy and Prevention. Praha: Galen, 2007. 239 pp. ISBN 978-80-7262-466-9.

20. PAVELEKOVA I, PETERKOVA V (2011) Are Obese Parent's Obese Children? Proceedings 1 School and Health 21. [online]. No.1. pp. 169-179. [cited 2011-04]. Available on Internet: http:/www.ped.muni.cz/ z21/knihy/201138/texty/cze/2_peterkova_ pavelekova.pdf.

21. PROCHOTSKA K, KOVACS L (2016) What's New in Childhood Obesity? In: Bedeker Health. Bratislava: RE - PUBLIC, May No. 03, Vol. XII, pp. 26 - 27. ISSN 1337-2734.

22. SVACINA S, BRETSNAJDROVAA (2008) How about Obesity and its Complications. Praha: Grada Publishing, 144 pp. ISBN 978-80-247-2395-2.

23. VITARIUSOVA E, BABINSKA K, ROSINSKY J et al. 2009. Physical Activity and Composition of Leisure Time in the Population of Children in the Slovak Republic. Pediatrics for Practice. [online]. Solen. 10. Grade. No 02/2009. pp. 94-97. [cited 2009]. ISNN 1339-4231. Available on the Internet: http://www.pediatriapreprax.com/index. php?Page=pdf_view\&pdf_id=3687\& magazine_id $=4$. 
24. VITEK L (2008) How to Influence Overweight and Obesity. Praha: Grada Publishing, 160 pp. ISBN 978-80-247-2247-4.
25. National Action Plan on the Prevention of Obesity for 2015-2025. [Online]. Available on Internet: http://www.uvzsr.sk/docs/info/ podpora/NAPPO_2015-2025.pdf. 